\title{
Graphene Oxide-Silica Composite Fillers into the Experimental Dental Adhesives for Potential Therapy
}

\author{
Mei Liu, Wei Hou, Wenjing Chen, and Xiaokun Hu* \\ Jiangsu Key Laboratory of Oral Diseases, Nanjing Medical University, Nanjing, Jiangsu 210029, China
}

\begin{abstract}
The aim of this study was to investigate the benefits of incorporation of graphene oxide-silica $\left(\mathrm{GO} @ \mathrm{SiO}_{2}\right)$ on the degree of conversion and bond strength of an experimental dental adhesive. The $\mathrm{GO} @ \mathrm{SiO}_{2}$ nanocomposites were prepared and characterized by using FTIR, Raman and TEM. After that, $\mathrm{GO} @ \mathrm{SiO}_{2}$ was added into an experimental dental bonding system as novel nanofiller, and the effect of the modification on the dispersion stability of the $\mathrm{GO} @ \mathrm{SiO}_{2}$ nanocomposites in the experimental adhesive was studied. In addition, the degree of conversion was characterized by real-time FTIR, and the light conversion kinetic curves were calculated. Furthermore, the bond strength of the experimental adhesive to dental restorative resin was investigated. The result showed that the $\mathrm{GO} @ \mathrm{SiO}_{2}$ nanocomposites dispersed well in the experimental adhesive, and the introduction of $\mathrm{GO} @ \mathrm{SiO}_{2}$ improved effectively the degree of conversion of the dental adhesive after curing. In addition, the experimental adhesive filled with $\mathrm{GO} @ \mathrm{SiO}_{2}$ nanocomposites showed not only similar bond strength to a commercial adhesive, but also enhanced dramatically compressive strength as well. Furthermore, the obtained experimental dental adhesives can increase reactive oxygen species level in cells through photothermal conversion to be used in potential therapy.
\end{abstract}

Keywords graphene oxide-silica, degree of conversion, bonding strength, reactive oxygen species

\section{Introduction}

In recent years, inorganic filler/resin composites have attracted considerable interest in the field of dental restorative materials. The combined advantages of inorganic filler and polymer usually afford polymer composites with unique performances. Among them, $\mathrm{SiO}_{2}$ with various size and structure has been widely used to strengthen different composites. The wear behavior of the resin composites was effectively improved by introduction of bimodal silica nanostructures including silica nanoparticles and nanoclusters as co-fillers. ${ }^{[1]}$ For example, the resin composites have higher light transmission and adequate mechanical properties than ordinary resins with the addition of monodispersed $\mathrm{SiO}_{2}$ microspheres. ${ }^{[2]}$ In addition, the incorporation of the modified nanoclay provided a dental bond system with higher shear bond strength. ${ }^{[3]}$

Generally, silane coupling agent was used to improve the interface reaction between $\mathrm{SiO}_{2}$ nanoparticles and polymer. However, recently, GO served as an unconventional coupling agent of the silica filler and was found to enhance effectively the interfacial interaction of the epoxy/SiO${ }_{2}$-GO composites. ${ }^{[4]}$ Graphene oxide (GO) nanosheets are heavily oxygenated graphene with a great deal of epoxy, hydroxyl, and carboxyl functional groups on its basal planes. ${ }^{[5-8]}$ These functional groups make them more compatible with organic polymers and perform unique properties in many fields. Nonetheless, more unique and superior properties of GO for material applications continue to be recognized or discovered. For example, the previous report explored that the novel role of GO has the ability to generate reactive oxygen species (ROS) as potential co-therapeutics for a bioactive molecule to induce cell death. ${ }^{[9]}$ In this work, the $\mathrm{GO}-\mathrm{SiO}_{2}$ composite filler was fabricated and then introduced into a the experimental dental adhesive, in which the $\mathrm{GO}-\mathrm{SiO}_{2}$ composite can not only enhance their mechanical properties but only mediate cell ROS for potential therapy. The aim of this study was to evaluate its poten- tial application as novel reinforcement fillers for dental adhesives.

\section{Experimental}

\section{Materials}

2,2-Bis[4-(2-hydroxy-3-methylacryloxypropoxy)-phenyl] propane (Bis-GMA), triethylene glycol dimethacrylate (TEGDMA), 2-(dimethylamino)ethyl methacrylate (DMAEMA) and camphorquinone (CQ) were purchased from Sigma Aldrich. Hydroxy ethyl methacrylate (HEMA) was produced by Tokyo Chemical Industry. Tetraethyl orthosilicate (TEOS), (3-aminopropyl)triethoxysilane (APTES), ammonium hydroxide $(25 \%-28 \%)$ and ethyl alcohol were purchased from Sinopharm Chemical Reagent. These reagents were all analytical grade. Ortho Solo adhesive was produced by Ormco, America. Z350XT resin was produced by $3 \mathrm{M}$ ESPE, America.

\section{Methods}

The nano $\mathrm{SiO}_{2}$ spheres with a narrow size distribution were prepared by Stöber method, ${ }^{[10]}$ which comprised the base-catalyzed hydrolysis of TEOS in water-ethanol mixtures. In a typical process, 1.5 $\mathrm{mL}$ TEOS was added into a mixture of $50 \mathrm{~mL}$ ethanol, $1 \mathrm{~mL}$ deionized water and $1.5 \mathrm{~mL}$ aqueous ammonia. The mixture was stirred and kept at $40{ }^{\circ} \mathrm{C}$ for $3 \mathrm{~h}$ before $1 \mathrm{~mL}$ more TEOS was added and reacted for another $3 \mathrm{~h}$. The nano $\mathrm{SiO}_{2}$ spheres were finally collected by repeatedly centrifuging and washing with ethanol and then water to get rid of unreacted TEOS. After that, the nano $\mathrm{SiO}_{2}$ spheres were freeze dried at $-80^{\circ} \mathrm{C}$ to remove the water on their surface.

Then, the surface modification of $\mathrm{SiO}_{2}$ with APTES coupling agent was carried out by the following procedures: The silica spheres redispersed in methylbenzene $(1 \mathrm{~g} / 120 \mathrm{~mL})$ by sonication were mixed with $4 \mathrm{~mL}$ APTES, stirred at $80{ }^{\circ} \mathrm{C}$ for $24 \mathrm{~h}$, and then collected by centrifuging and washing as the method stated before.

\footnotetext{
* E-mail: huxiaokun80@126.com

Received September 6, 2017; accepted December 28, 2017.
} 
Finally, the $\mathrm{GO} @ \mathrm{SiO}_{2}$ nanocomposite was fabricated simply by mixing the aqueous solutions of modified $\mathrm{SiO}_{2}(20 \mathrm{mg} / \mathrm{mL})$ and commercial GO $(0.2 \mathrm{mg} / \mathrm{mL}$, provided by XFNANO in Nanjing, China) in a volume ratio of 10:1. These aqueous solutions were dispersed under mild magnetic stirring and sonication, respectively. The sediments were collected and washed with water for several times to remove the unbound GO, and then freeze-dried under vacuum.

\section{Characterization}

The morphology of the modified $\mathrm{SiO}_{2}$ spheres was investigated with a JEOL 2100F High Resolution Transmission Electron Microscopy (HRTEM) at an accelerator voltage of $200 \mathrm{kV}$. The GO@ $\mathrm{SiO}_{2}$ spheres with a content of $1 \mathrm{wt} \%$ was dispersed in ethanol, dropped onto the copper mesh and then dried before HRTEM.

The structure of the initial $\mathrm{SiO}_{2}$ nanoparticles was compared with those APTES or GO modified ones, using a Nicolet 6700 FTIR spectrometer. The spectra were measured with an attenuated total reflectance accessory (ATR). Each spectrum was acquired in transmittance mode on a diamond substrate by the accumulation of 32 scans with a resolution of $4 \mathrm{~cm}^{-1}$ and a spectral range of $4000-500 \mathrm{~cm}^{-1}$.

The Raman measurement was performed by a laser confocal micro-Raman spectrometer (Renishaw in-Via Reflex, US) using $532 \mathrm{~nm}$ excitation wavelength and $10 \% \times 50 \mathrm{~mW}$ power.

The fluorescence spectra of the GO solution $(0.01 \mathrm{~g} / \mathrm{mL})$ were recorded with a fluorescence spectrophotometer (F-7000, HITACHI, Japan). The spectra were respectively collected at 380, 400, 420 and $440 \mathrm{~nm}$ excitation, with an emission range of 380-600 nm every 1 $\mathrm{nm}$. The excitation and emission slits were both set to $2.5 \mathrm{~nm}$. The scan speed was $1200 \mathrm{~nm} / \mathrm{min}$.

\section{Stability of the adhesive}

The adhesive with 1 wt $\%$ of $\mathrm{GO} @ \mathrm{SiO}_{2}$ spheres was stored in darkness at $4{ }^{\circ} \mathrm{C}$ and were photographed at $0,8,24 \mathrm{~h}$ and $5 \mathrm{~d}$ to describe the dispersion stability of the modified $\mathrm{SiO}_{2}$ in the adhesive system.

\section{Measurement of degree of conversion}

The light conversion kinetic of the experimental dental adhesives, at ambient temperature, was investigated by real-time FTIR using a Thermo Scientific iS10 FTIR spectrometer at a resolution of $4 \mathrm{~cm}^{-1}$, before which the tested adhesives were cast on the infrared transparent silicon chips and then covered with a mylar film. A conventional LED light curing unit (400-500 nm, 1000-1200 $\mathrm{mW} / \mathrm{cm}^{2}$, Woodpecker, Guilin, China) was applied to cure the samples for $200 \mathrm{~s}$ and the spectra were continuously collected every $5 \mathrm{~s}$ for totally $300 \mathrm{~s}$.

Two characteristic bands, $1637 \mathrm{~cm}^{-1}$ (stretching of methacrylate double bond $\mathrm{C}=\mathrm{C}$ ) and $1608 \mathrm{~cm}^{-1}$ (stretching of phenyl group) were employed to calculate the degree of conversion (DC) of photopolymerization. The changes in absorbance ratios of $1637 \mathrm{~cm}^{-1} / 1608 \mathrm{~cm}^{-1}$ were monitored and DC could be calculated by using the following equation: ${ }^{[11,12]} \mathrm{DC}=[1-($ ACure 1637/ACure 1608)/(AMonomer 1637/ AMonomer 1608)] $\times 100 \%$, where ACure 1637 was absorbance of cured adhesive at $1637 \mathrm{~cm}^{-1}$, ACure 1608 was absorbance of cured adhesive at $1608 \mathrm{~cm}^{-1}$, AMonomer 1637 was absorbance of uncured adhesive at $1637 \mathrm{~cm}^{-1}$, and AMonomer 1608 was absorbance of uncured adhesive at $1608 \mathrm{~cm}^{-1}$.

\section{Mechanical properties}

The bond strength was characterized using Shenzhen SUNS UTM4104 Universal Testing Machine. A special clamp was designed and installed on the mechanical testing machine, with its upper slider moving freely while the lower slide static. Two Z350XT resin sticks $(2 \mathrm{~mm} \times 2 \mathrm{~mm} \times 10 \mathrm{~mm}$ ) were fixed in the rectangular grooves on the clamp. Then the experimental adhesives were evenly coated on the sides between the two sticks and cured by the LED light curing unit for $2 \mathrm{~min}$. The samples were then tested with a $100 \mathrm{~N}$ capacity load cell at a crosshead speed of $4 \mathrm{~mm} / \mathrm{min}$.

The compressive strengths of the experimental adhesives were also tested on the Universal Testing Machine. The adhesives were molded into columns (radius, $2 \mathrm{~mm}$; height, $6 \mathrm{~mm}$ ) and cured for 1 min on each side using the LED light unit. They were stored in distilled water at ambient temperature for $40 \mathrm{~h}$ to ensure that polymerization was completed and the rest of the monomers were dissolved. The compressive strength was determined according to equation: $\mathrm{CS}=4 F /\left(\pi d^{2}\right)$, where $F$ was the maximum load measured with the universal testing machine at a crosshead speed of $1 \mathrm{~mm} / \mathrm{min}$.

\section{Measurement of ROS}

Intracellular reactive oxygen species (ROS) generation of healthy human dental pulp cells was measured by 2',7'-dichlorofluorescin diacetate (DCFH-DA). After cellular uptake of DCFH-DA, it was cleaved by cellular esterases to 2',7'-dichlorofluorescin (DCFH), and the intracellular ROS would cause the oxidation of DCFH to the fluorescent product of 2',7'-dichlorofluorescein (DCF). Cells plated on 6-well cell culture plates were maintained, and then DMEM was replaced with the medium containing the obtained experimental dental adhesives. The cell was after irradiated, after which cells were washed and incubated with DCFH-DA $(10 \mu \mathrm{M})$ in serum-free culture medium. The medium was removed, and cells were washed three times with PBS. The DCF fluorescence intensity was measured using fluorescence microscopy excited by blue light and was also detected by a flow cytometer with an excitation wavelength of $488 \mathrm{~nm}$ after cells should be digested with trypsin enzyme first and washed three times with PBS through a centrifuge $\left(1000 \mathrm{rpm}, 3 \mathrm{~min}, 4{ }^{\circ} \mathrm{C}\right)$.

\section{Cytotoxicity experiment}

The cytotoxic effect of the adhesives with or without fillers was determined with the CCK-8 assay. The adhesives disks with a diameter of $10 \pm 1 \mathrm{~mm}$ and a thickness of $1 \pm 0.1 \mathrm{~mm}$ were prepared by filling the adhesives into a silica rubber mold and light curing for $1 \mathrm{~min}$. After that, the disks were immersed in $75 \%$ alcohol for $30 \mathrm{~min}$, washed with PBS, and then soaked in $5 \mathrm{~mL}$ DMEM (containing $10 \%$ FBS, $100 / \mathrm{mL}$ penicillin and $100 \mu \mathrm{g} / \mathrm{mL}$ streptomycin) in a sterile environment at $37{ }^{\circ} \mathrm{C}$ for $4 \mathrm{~d}$. The extract liquids were collected and filtered using a syringe-driven filter to ensure no bacteria. Then the sterilized extract liquids (diluted with DMEM as 1:0, 1:5 and 1:10) were set as the groups, and the untreated DMEM as the control group.

Healthy human dental pulp cells (HDPC) were regularly cultured and passaged in DMEM medium at $37^{\circ} \mathrm{C}$ and $5 \% \mathrm{CO}_{2}$. The cells suspension $\left(5 \times 10^{5}\right.$ cells $\left./ \mathrm{mL}\right)$ was seeded in a 96 -well plate ( $200 \mu \mathrm{L}$ medium per well) and cultured for $48 \mathrm{~h}$ to make the cells well attached and proliferated. Then the medium was substituted with the above experimental groups and control group extract liquid. After $24 \mathrm{~h}$, the cells morphology was observed by an inverted microscopy (Leica DMI 4000B, Germany). Then $100 \mu \mathrm{L}$ CCK- 8 solution ( $10 \%$ in volume) was added into each well and the cells were incubated for another $2 \mathrm{~h}$. Cell viability was measured with the MB-40 ELISA microplate reader by recording the absorbance at $450 \mathrm{~nm}$. The number of the survival cells was calculated as the ratio of the mean absorbance of experimental groups to the mean absorbance of control group.

\section{Results and Discussion}

To prepare GO@ $\mathrm{SiO}_{2}$, the $\mathrm{SiO}_{2}$ spherical particles were firstly reacted with APTES to modify the $\mathrm{SiO}_{2}$ surface with $\mathrm{NH}_{2}$ groups. This made the $\mathrm{SiO}_{2}$ surface positively charged in aqueous solution. While GO nanosheets contained a large number of hydroxyl and carboxylic groups on the surface, $\mathrm{GO} @ \mathrm{SiO}_{2}$ could thus be obtained by mixing the negatively charged GO nanosheets and positively charged APTES@SiO $\mathrm{SiO}_{2}$ particles in an aqueous solution, which im- 
mobilized $\mathrm{GO}$ onto the $\mathrm{SiO}_{2}$ surface through electrostatic assembly mechanism. ${ }^{[13]}$ The $\mathrm{SiO}_{2}$ nanoparticles had a diameter of about $70 \mathrm{~nm}$ with a sphere morphology and smooth surface (Figure 1a). As shown in Figure 1b, ultrathin GO (blue arrow) intimately wrapped the $\mathrm{SiO}_{2}$ nanoparticles (red arrow). The typical HRTEM images of $\mathrm{GO} @ \mathrm{SiO}_{2}$ composite filler (Figure 1c) also confirmed that the flexible and ultrathin GO sheets had indeed successfully wrapped around the $\mathrm{SiO}_{2}$ nanoparticles. As shown in Figure 1d, no obvious aggregation was observed in the $\mathrm{GO} @ \mathrm{SiO}_{2}$ composite filler.

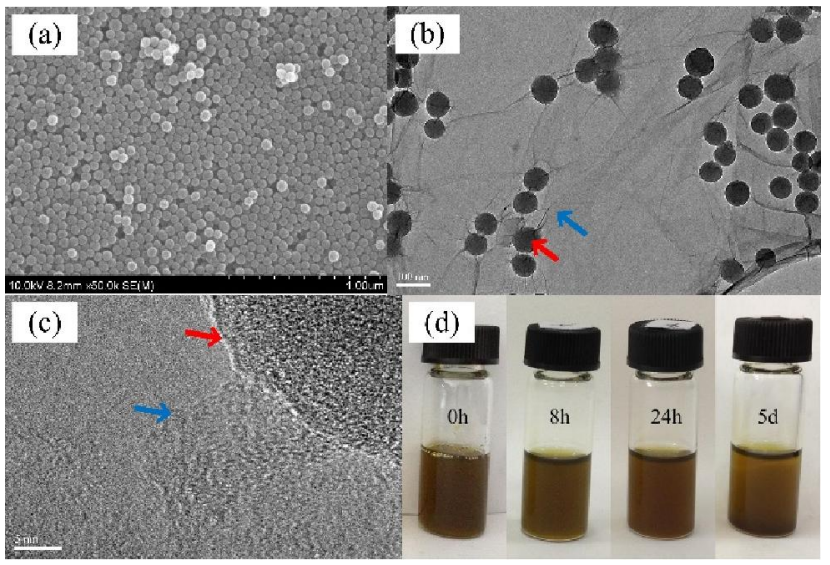

Figure 1 TEM images of the (a) raw $\mathrm{SiO}_{2}$ and (b) created $\mathrm{GO} @$ $\mathrm{SiO}_{2}$ hybrid, scale bar 100 nm, (c) HRTEM images of GO@ $\mathrm{SiO}_{2}$ (scale bar $5 \mathrm{~nm}$ ), (d) dispersion of $\mathrm{GO} @ \mathrm{SiO}_{2}$ in the light-cured experimental dental adhesives at $0,8,24 \mathrm{~h}$ and $5 \mathrm{~d}$.

The structure of $\mathrm{GO} @ \mathrm{SiO}_{2}$ was characterized by FTIR and Raman. As shown in Figure 2a, the main peaks of $\mathrm{SiO}_{2}$ spectra curve at $797,1050,1626 \mathrm{~cm}^{-1}$ and the broad band around $3350 \mathrm{~cm}^{-1}$ were identified as symmetric vibrations of $\mathrm{Si}-\mathrm{O}-\mathrm{Si}$, asymmetric vibrations of $\mathrm{Si}-\mathrm{O}-\mathrm{Si}$, bending vibration of $\mathrm{O}-\mathrm{H}$ and stretching vibration of $\mathrm{OH},{ }^{[14-16]}$ respectively. After surface modification by APTES, the broad band at $3350 \mathrm{~cm}^{-1}$ became weak, which indicated the decrease of hydroxyl on $\mathrm{SiO}_{2}$ surface. Furthermore, new characteristic peaks around $1500 \mathrm{~cm}^{-1}$ belonging to $\mathrm{N}-\mathrm{H}$ bending vibration were observed. ${ }^{[15]}$ Several minor bands at around 2800 to $3000 \mathrm{~cm}^{-1}$ were also detected in the spectra of APTES@ $\mathrm{SiO}_{2}$, which were attributed to the $\mathrm{N}-\mathrm{H}$ stretching vibration. ${ }^{[16]}$ As $\mathrm{GO}$ has a large amount of $\mathrm{OH}$ groups, the broad band around $3350 \mathrm{~cm}^{-1}$ of $\mathrm{GO} @ \mathrm{SiO}_{2}$ was higher than that of APTES@ $\mathrm{SiO}_{2}$. In addition, Raman spectroscopy, which was utilized as a powerful tool for the characterization of graphene and its derivatives, was employed to further identify the $\mathrm{GO} @ \mathrm{SiO}_{2}$. As shown in Figure $2 b$, we could see two intensive peaks at 1355 and $1598 \mathrm{~cm}^{-1}$ on both GO and $\mathrm{GO} @ \mathrm{SiO}_{2}$ curves. They were referred to the $\mathrm{D}$ band, resulting from a disordered $\mathrm{sp} 3$ carbon structure, and the $\mathrm{G}$ band representing $\mathrm{sp} 2$ ordered crystalline graphite-like structures, respectively. ${ }^{[17,18]}$ Interestingly, a little increased ratio of $I(\mathrm{D}) / I(\mathrm{G})$ was found on the curve of $\mathrm{GO} @ \mathrm{SiO}_{2}$ compared to GO. It had been
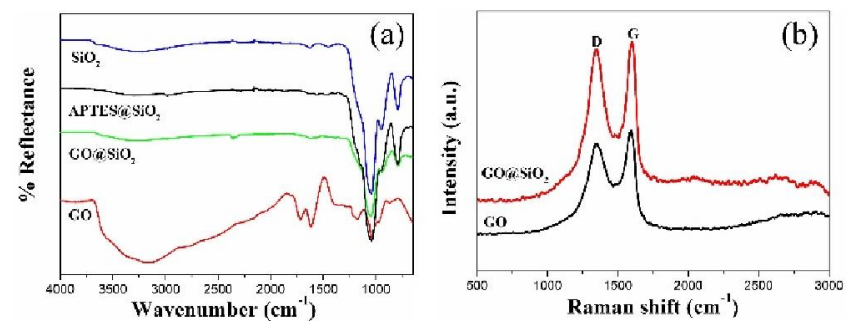

Figure 2 FTIR spectra curves (a) of pristine $\mathrm{SiO}_{2}$, APTES@ $\mathrm{SiO}_{2}$, $\mathrm{GO} @ \mathrm{SiO}_{2}$, and GO; Raman spectra (b) of the $\mathrm{GO} @ \mathrm{SiO}_{2}$ and GO. reported that the increase of $I(\mathrm{D}) / I(\mathrm{G})$ ratio reflected the increase of disorder present within the materials. ${ }^{[19]}$ Thus the enhanced ratio for $\mathrm{GO} @ \mathrm{SiO}_{2}$ proved that $\mathrm{GO}$ was assembled onto $\mathrm{SiO}_{2}$, rather than a kind of mechanical mixture.

The GO@ $\mathrm{SiO}_{2}$ composite was then added into the experimental dental adhesive. The adhesive was prepared mainly composing of Bis-GMA, TEGDMA and HEMA. CQ/DMAEMA was used as the co-initiator of the dental adhesives. $\mathrm{GO} @ \mathrm{SiO}_{2}$ composite fillers with the content of $1 \mathrm{wt} \%$ were added into the dental adhesive by stirring and sonication. After that, the dental adhesive was stored in darkness at $4{ }^{\circ} \mathrm{C}$ and was photographed at $0,8,24 \mathrm{~h}$ and $5 \mathrm{~d}$, respectively. Either at 8 or $24 \mathrm{~h}$, no significant sedimentation was observed. Only a small amount of precipitation was found after $5 \mathrm{~d}$. Therefore, the $\mathrm{GO} @ \mathrm{SiO}_{2}$ composite fillers had preliminary dispersion stability in the experimental dental adhesives. The light conversion kinetic of the experimental dental adhesive was investigated by the real-time FTIR. Representative real-time spectra of the pristine experimental dental adhesive and adhesives filled with 1 wt $\%$ APTES@ $\mathrm{SiO}_{2}$ and $1 \mathrm{wt} \%$ $\mathrm{GO} @ \mathrm{SiO}_{2}$ were recorded during photopolymerization, as shown in Figure 3. It was clearly discerned that the absorbance of $\mathrm{C}=\mathrm{C}$ at 1637 $\mathrm{cm}^{-1}$ decreased with increasing the polymerization time, indicating the polymerization of the monomers in the dental adhesives. In addition, the DC of the adhesive filled with $1 \mathrm{wt} \% \mathrm{GO} @ \mathrm{SiO}_{2}$ reached $52.1 \%$, which was almost two times higher than the DC of pristine adhesive of $26.6 \%$. This result indicated that DC of the experimental adhesive was distinctly enhanced with the addition of $\mathrm{GO} @ \mathrm{SiO}_{2}$.
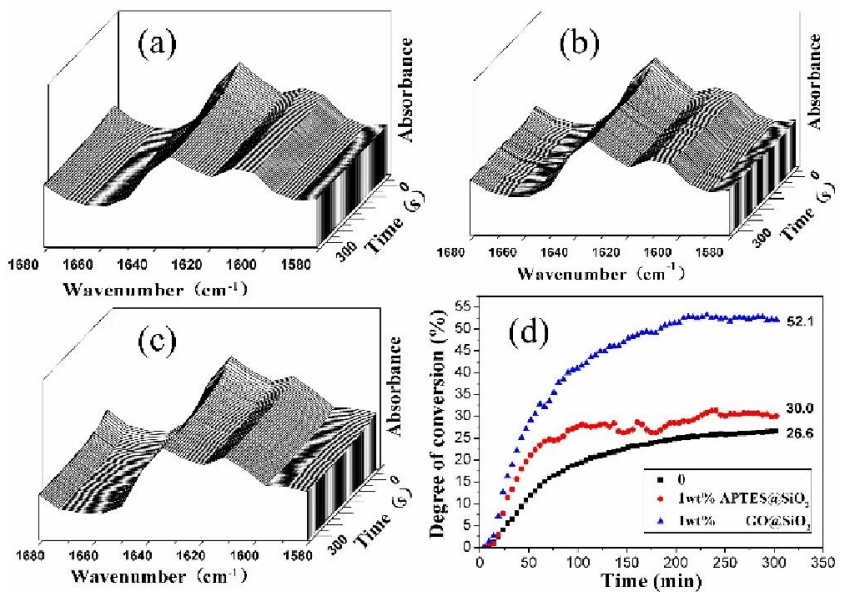

Figure 3 The time-resolved FT-IR spectrum of the experimental dental adhesives: (a) no GO@ $\mathrm{SiO}_{2}$, (b) 1 wt\% APTES@SiO 2 , (c) 1 wt\% $\mathrm{GO} @ \mathrm{SiO}_{2}$ and (d) their light conversion kinetic curves.

The enhancement on DC of the $\mathrm{GO} @ \mathrm{SiO}_{2}$ filled adhesive was attributed to two reasons. Firstly, the GO nanosheets used in this study showed photoluminescent (PL) peaks at $413,438,465$, and 491 $\mathrm{nm}$ when excited respectively at 360,380, 400 and $420 \mathrm{~nm}$ (in Figure 4), which showed a similar property to the graphene quantum dots (GQDs). Zhu et al. synthesized kinds of strongly fluorescent GQDs containing many chemical groups such as $\mathrm{OH}$, epoxy/ether, $\mathrm{C}=\mathrm{O}$ and $-\mathrm{CO}-\mathrm{NH}_{2}$. When GQDs were excited at wavelengths from 400 to 540 $\mathrm{nm}$, their PL peak shifted from 515 to $570 \mathrm{~nm} .{ }^{[20]}$ Considering the CQ/DMAEMA co-initiator was reported to be excited at the wavelength of $400-500 \mathrm{~nm},{ }^{[21]}$ the PL light from GO enhanced the intensity of the curing light in the experimental adhesive when it was exposed under the LED light curing unit. Thus more free radicals were generated in the $\mathrm{GO} @ \mathrm{SiO}_{2}$ filled adhesive, which resulted in higher polymerization rate and degree of conversion. Secondly, the adhesive got higher viscosity as the reaction progress, which led to the "gel" effect ("Trommsdorff" effect). ${ }^{[22]}$ Polymerization rate was increased 
at high viscosities due to a reduction in chain termination accompanying the decreased mobility of the polymer radicals. Actually, when the adhesive was exposed under the LED light curing unit, amine radicals were formed in the experimental adhesive and could be enriched around GO sheets through physical or chemical adsorptions. ${ }^{[23]}$ Therefore, GO could enhance the degree of conversion by absorption of the radicals and decreasing their mobility.

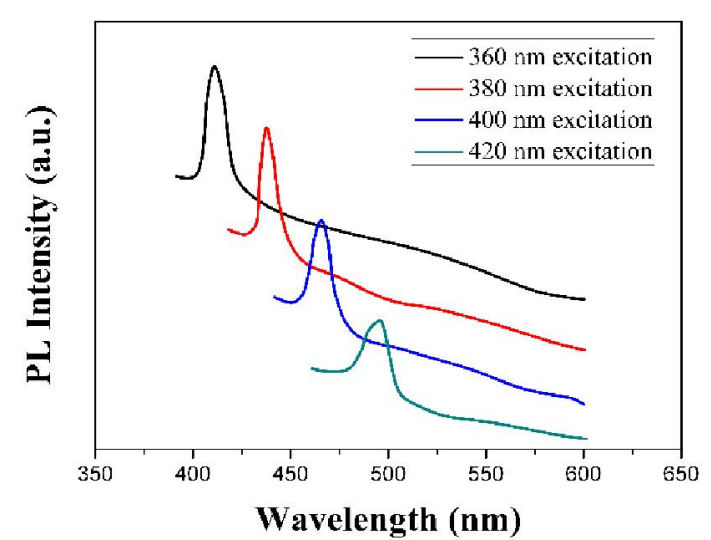

Figure 4 The excitation-dependent PL behavior of GO nanosheets.

A universal mechanical machine was used to test the microtensile bond strength and the compressive strength of the experimental dental adhesives. Microtensile bond test has now been accepted as a reliable and facile method in measuring the bond strength of dental adhesives. In order to overcome the drawback of the traditional testing method which needed additional adhesives to set the resin sticks on the testing platform, a special self-made clamp was designed. Figure 5 showed the means and standard deviations of the bond or compressive strength of adhesive with 1 wt $\% \mathrm{GO} @ \mathrm{SiO}_{2}$ and a commercial Ortho Solo adhesive (Ormco, America). The adhesive filled with $\mathrm{GO} @ \mathrm{SiO}_{2}$ had bond strength of $20.9 \mathrm{MPa}$, which was similar to the Ortho Solo adhesives, about $21.03 \mathrm{MPa}$. While the compressive strength of the adhesives filled with $\mathrm{GO} @ \mathrm{SiO}_{2}$ reached $219.3 \mathrm{MPa}$, it was much higher than the $150.8 \mathrm{MPa}$ of the commercial adhesive.

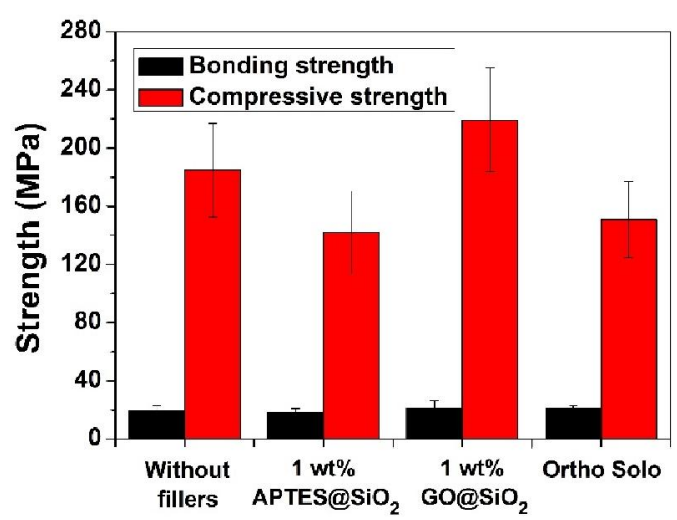

Figure 5 Bonding and compressive strength of the adhesive without fillers and with 1 wt\% APTES@ $\mathrm{SiO}_{2}$ and $\mathrm{GO} @ \mathrm{SiO}_{2}$ and a commercial adhesive.

As we well known, ROS may serve as good candidates for combination therapy with a bioactive molecule. ${ }^{[9]}$ Furthermore, various ROS inducing agents like apigenin and emordin have been reported to sensitize cancer cells to conventional anti-cancer agents like paclitaxel, cisplatin, doxorubicin and arsenic trioxide. ${ }^{[24-25]}$ Additionally, the hyperthermia treatments $\left(43-45{ }^{\circ} \mathrm{C}\right)$ cause long term cell inactivation due to the increment of the intracellular density of reactive oxygen species, which can cause oxidative damage to proteins, lipids and nucleic acids. ${ }^{[26]}$ Furthermore, GO has the ability to generate ROS. Therefore, the photothermal conversion performance of $1 \mathrm{wt} \%$ $\mathrm{GO} @ \mathrm{SiO}_{2}$ suspension, experimental dental adhesives with $1 \mathrm{wt} \%$ $\mathrm{GO} @ \mathrm{SiO}_{2}$ and pure water with different time was examined using the irradiation of $980 \mathrm{~nm}$ laser with a power density of $2 \mathrm{~W} / \mathrm{cm}^{2}$. As shown in Figure 6a, it is found that 1wt\% GO@ $\mathrm{SiO}_{2}$ suspension can be heated by up to $54.3{ }^{\circ} \mathrm{C}$ in the period of $240 \mathrm{~s}$, demonstrating that the $\mathrm{GO} @ \mathrm{SiO}_{2}$ composite can rapidly and efficiently convert $980 \mathrm{~nm}$ laser energy into thermal energy, compared with the control experiment of pure water that is only increased by less than $5{ }^{\circ} \mathrm{C}$. Moreover, the obtained experimental dental adhesives with 1 wt $\% \mathrm{GO} @ \mathrm{SiO}_{2}$ can increase the temperature of pure water from 24.9 to $40.3{ }^{\circ} \mathrm{C}$ in the same irradiation time of $240 \mathrm{~s}$, which reveals that the obtained experimental dental adhesives possess comparable optical absorption characteristic and the photothermal conversion performance. Furthermore, ROS in cells were measured by $2^{\prime}, 7^{\prime}$-dichlorofluorescin diacetate (DCFH-DA). There is almost little 2',7'-dichlorofluorescein (DCF) fluorescence in the controlled group after $240 \mathrm{~s}$ irradiation (Figure 6b), which implies that the ROS level in cells cultured without addition is very low. However, green cells from DCF fluorescence can be seen clearly in the fluorescent microscopic image with the addition of 1 wt $\% \mathrm{GO} @ \mathrm{SiO}_{2}$ to dental adhesives (Figure $6 \mathrm{c}$ ). The results show that the obtained experimental dental adhesives can be used in potential therapy because of ROS through photothermal conversion.
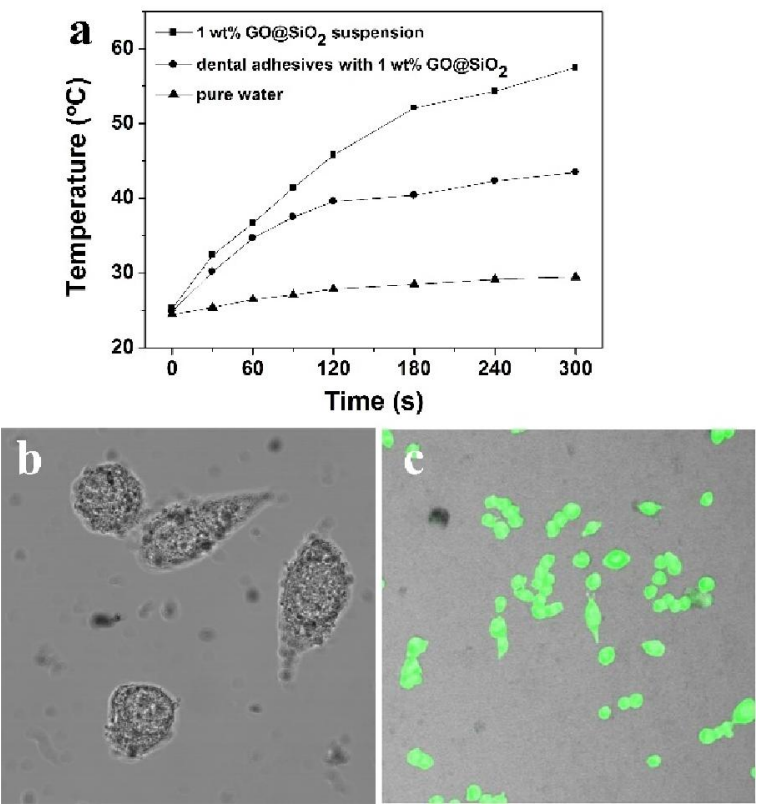

Figure 6 (a) Temperature elevation of 1 wt $\%$ GO@ $\mathrm{SiO}_{2}$ suspension, experimental dental adhesives with $1 \mathrm{wt} \% \mathrm{GO} @ \mathrm{SiO}_{2}$ and pure water with different time using the irradiation of $980 \mathrm{~nm}$ laser with a power density of $2 \mathrm{~W} / \mathrm{cm}^{2},(\mathrm{~b}-\mathrm{c})$ the fluorescent microscopic images of cellular ROS production after $240 \mathrm{~s}$ irradiation.

The cytotoxicity to the HDPCs of the dental adhesives was evaluated by CCK- 8 test, as shown in Figure 7. The results demonstrated that the cells proliferated better with dilution of the extract liquid and the increasing of DC, and that the experimental adhesives showed slighter cytotoxicity than the commercial Ortho Solo adhesive.

\section{Conclusions}

In conclusion, this research provided evidence that GO coating on silica particle had preliminary dispersion stability in the experimental dental adhesives. The GO@ $\mathrm{SiO}_{2}$ nanocomposite filler largely 


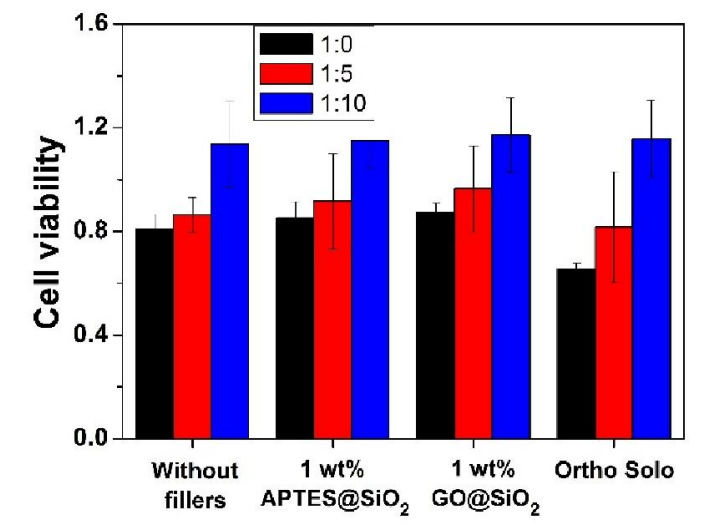

Figure 7 The cell viability of the adhesive without fillers and with 1 wt\% APTES@SiO $\mathrm{Si}_{2}$ and $\mathrm{GO} @ \mathrm{SiO}_{2}$, and a commercial adhesive.

enhanced the degree of conversion of the dental adhesives. Additionally, the dental adhesives filled with $\mathrm{GO} @ \mathrm{SiO}_{2}$ had a similar bond strength to commercial adhesive and a significantly higher compressive strength than the commercial adhesive. Furthermore, the GO$\mathrm{SiO}_{2}$ composite in the experimental dental adhesive can mediate cell ROS for potential therapy. The concept of using $\mathrm{GO} @ \mathrm{SiO}_{2}$ nanocomposite as novel filler provided a powerful way to control composites interfacial structure and properties.

\section{Acknowledgement}

This work was supported by the Priority Academic Program Development of Jiangsu Higher Education Institutions (PAPD, No. 2014-37).

\section{References}

[1] Wang, R.; Bao, S.; Liu, F.; Jiang, X.; Zhang, Q.; Sun, B.; Zhu, M. Mat. Sci. Eng. C 2013, 33, 4759.

[2] Miao, X.; Li, Y.; Zhang, Q.; Zhu, M.; Wang, H. Mat. Sci. Eng. C 2012 , $32,2115$.

[3] Solhi, L.; Atai, M.; Nodehi, A.; Imani, M.; Ghaemi, A.; Khosravi, K. Dent. Mater. 2012, 28, 369.

[4] Chen, L.; Liu, S. K.; Ning, N.; Gao, J.; Liu, Q.; Chen, F.; Fu, Q. ACS
Appl. Mater. Inter. 2012, 4, 4398.

[5] Bagri, A.; Mattevi, C.; Acik, M.; Chabal, Y. J.; Chhowalla, M.; Shenoy, V. B. Nat. Chem. 2010, 2, 581.

[6] Stankovich, S.; Dikin, D. A.; Piner, R. D.; Kohlhaas, K. A.; Kleinhammes, A.; Jia, Y.; Wu, Y.; Nguyen, S. T. Ruoff, R. S. Carbon 2007, 45,1558 .

[7] Stankovich, S.; Piner, R. D.; Nguyen, S. T.; Ruoff, R. S. Carbon 2006 44, 3342.

[8] Yin, K.; Li, H.; Xia, Y.; Bi, H.; Sun, J.; Liu, Z.; Sun, L. Nano-Micro Lett. 2011, 3, 51 .

[9] Arya, N.; Arora, A.; Vasu, K. S.; Soodb, K.; Katti, D. S. Nanoscale 2013 , $5,2818$.

[10] Rahman, I. A.; Padavettan, V. J. Nanomater. 2012, 2012, 8.

[11] Guo, X.; Wang, Y.; Spencer, P.; Ye, Q.; Yao, X. Dent. Mater. 2008, 24, 824.

[12] Venhoven, B. A. M.; de Gee, A. J.; Davidson, C. L. Biomaterials 1996, 17,2313

[13] Liu, J. W.; Zhang, Q.; Chen, X. W.; Wang, J. H. Chem. Eur. J. 2011, 17, 4864.

[14] Kursunlu, A. N.; Guler, E.; Dumrul, H.; Kocyigit, O.; Gubbuk, I. H. Appl. Surf. Sci. 2009, 255, 8798

[15] Uruş, S.; Dolaz, M.; Tümer, M. J. Inorg. Organomet. Polymer Mater 2010, 20, 706

[16] İspir, E.; Serin, S.; Therm, J. Anal. Calorim. 2008, 94, 281.

[17] Kou, L.; Gao, C. Nanoscale 2011, 3, 519.

[18] Paredes, J. I.; Villar-Rodil, S.; Solís-Fernández, P.; Martínez-Alonso A. Tascón, J. M. D. Langmuir 2009, 25, 5957.

[19] Kudin, K. N.; Ozbas, B.; Schniepp, H. C.; Prud'homme, R. K.; Aksay, I. A.; Car, R. Nano Lett. 2008, 8, 36.

[20] Zhu, S.; Zhang, J.; Qiao, C.; Tang, S.; Li, Y.; Yuan, W.; Li, B.; Tian, L. Liu, F.; Hu, R.; Gao, H.; Wei, H.; Zhang, H.; Sun, H.; Yang, B. Chem. Commun. 2011, 47, 6858.

[21] Pilo, R.; Oelgiesser, D. Cardash, H. S. J. Dent. Res. 1999, 27, 235.

[22] Oguri, M.; Yoshida, Y.; Yoshihara, K.; Miyauchi, T.; Nakamura, Y.; Shimoda, S.; Hanabusa, M.; Momoi, Y.; Van Meerbeek, B. Acta Biomater. 2012, 8, 1928

[23] Wang, F. T.; Chen, L.; Tian, C. J.; Meng, Y.; Wang, Z. G.; Zhang, R. Q.; Jin, M. X.; Zhang, P.; Ding, D. J. J. Comput. Chem. 2011, 32, 3264.

[24] Yi, J.; Yang, J.; He, R.; Gao, F.; Sang, H.; Tang, X.; Ye, R. D. Cancer Res. 2004, 64, 108.

[25] Wang, J. Yi, J. Cancer Biol. Ther. 2008, 7, 1875.

[26] Jaque, D.; Maestro, L. M.; del Rosal, B.; Gonzalez, P. H.; Benayas, A.; Plaza, J. L.; Rodríguez, E. M.; Solé, J. G. Nanoscale 2014, 6, 9494. 